\title{
Effect of Heat Treatment Temperature on the Growth of Al / Ti Joining Interface Reaction Layer
}

\author{
Jiuyong $\mathrm{Li}^{1, \mathrm{a}}$, Ranfeng Qiu, ${ }^{1,2, \mathrm{~b}}$, Yangyang Zhao ${ }^{1, \mathrm{c}}$ and Hengbo $\mathrm{Ma}^{1, \mathrm{~d}}$ \\ ${ }^{1}$ School of Materials Science and Engineering, Henan University of Science and Technology, \\ Luoyang, 471003, China \\ ${ }^{2}$ Collaborative Innovation Center of Nonferrous Metals, Henan Province, Luoyang, China \\ a2438596434@qq.com, bqiurf1221@163.com, c1053223247@qq.com, d1787180087@qq.com
}

Keywords: Heat treatment; Aluminum alloy; Titanium; Reaction layer.

Abstract. In this paper, aluminum alloy and titanium as the research object, the resistance spot welding and post-weld heat treatment were conducted to study the Al/Ti interface reaction layer formation and growth characteristics. Besides, the effect of heat treatment temperature on the growth of $\mathrm{Al} / \mathrm{Ti}$ bonded interface was investigated under the same heat treatment time. The results show that TiAl3 is the only new phase formed during the heat preservation process. At the same holding time, the thickness of the Al/Ti interface reaction layer increases exponentially with the increase of the heat treatment temperature.

\section{Introduction}

The connection of new materials and dissimilar materials is the product of modern high-tech development, which penetrates with other disciplines and promotes each other. It has become the frontier and pillar of new technology. With the rapid development of modern industry and the continuous progress of science and technology, the comprehensive performance requirements of parts and components is also increasing, and a single metal structure is usually difficult to meet the needs of industrial production [1].

Aluminum and Titanium are widely used in excellent materials, and their applications are highly crossed [2]. In some specific occasions, titanium or aluminum alloy components have a specific use requirements. It is necessary to connect the titanium and aluminum to form a composite member, which can reduce the quality of the components, but also to a large extent to play the advantages of the two metals. Titanium / aluminum composite structure in aerospace, weapons and equipment, ship machinery and other fields have a wide range of applications, such as the aircraft wing is the titanium alloy and aluminum alloy honeycomb sandwich connection and the formation of the composite structure [3-5].

In this paper, the aluminum alloy plate and the titanium plate were connected by resistance spot welding method. The formation process and growth characteristics of the Al/Ti interface reaction layer were observed, and the interface product was determined.

\section{Experimental procedures}

In this study, materials used were A6061 aluminum alloy sheets with thickness of $2.0 \mathrm{~mm}$ and pure titanium sheets with thickness of $1.0 \mathrm{~mm}$. Their chemical compositions are listed in Table 1. Prior to welding, the aluminum alloy and pure titanium sheets were grinded by using abrasive paper and degreased in acetone in sequence.

Table 1 chemical composition of materials

\begin{tabular}{cccccccccccc}
\hline Materials & $\mathrm{Ti}$ & $\mathrm{C}$ & $\mathrm{N}$ & $\mathrm{O}$ & $\mathrm{Fe}$ & $\mathrm{Mn}$ & $\mathrm{Cr}$ & $\mathrm{Cu}$ & $\mathrm{Si}$ & $\mathrm{Mg}$ & $\mathrm{Al}$ \\
\hline $\mathrm{Ti}$ & $\mathrm{Bal}$. & 0.01 & 0.02 & 0.14 & 0.07 & - & - & - & - & - & - \\
$\mathrm{A} 6061$ & 0.15 & - & - & - & - & 0.15 & 0.04 & 0.3 & 0.6 & 1.0 & $\mathrm{Bal}$. \\
\hline
\end{tabular}


Annealing experiments were carried out at $550,575,600,630^{\circ} \mathrm{C}\left( \pm 0.5^{\circ} \mathrm{C}\right)$ for $9 \mathrm{~h}$ under ambient atmosphere in a furnace. After annealing, the specimens were cooled in air and prepared for metallographic examination by sectioning transverse to the reaction interface. All specimens were mounted in epoxy resin and grinding was performed on silicon carbide paper. This was followed by polishing using $2.5 \mu \mathrm{m}$ diamond and $0.25 \mu \mathrm{m}$ diamond. The thickness of the $\mathrm{Ti} / \mathrm{Al}$ interface reaction layers was measured from scanning electron microscope (SEM, JEOL JSM-6300) micrographs of the cross-sections. For each experiment condition, an average thickness was measured from 10 individual measurement results. An energy dispersive X-ray spectroscopy (EDX) was used to determine intermetallic compounds formed during annealing experiments.

\section{Results and discussions}

Fig. 1 shows a scanning electron micrograph of interface region under aluminum / titanium welded joints without heat treatment. EDX analysis shows that the gray area in the figure is pure titanium and the black area is aluminum. As illustrated in Fig. 1, the interfaces between the titanium sheets and aluminum sheets were fairly straight. No voids and cracks were observed near the interface region indicating a good physical contact condition between the titanium and aluminum. And no formation of any intermetallic compound was observed at the titanium / aluminum interface.

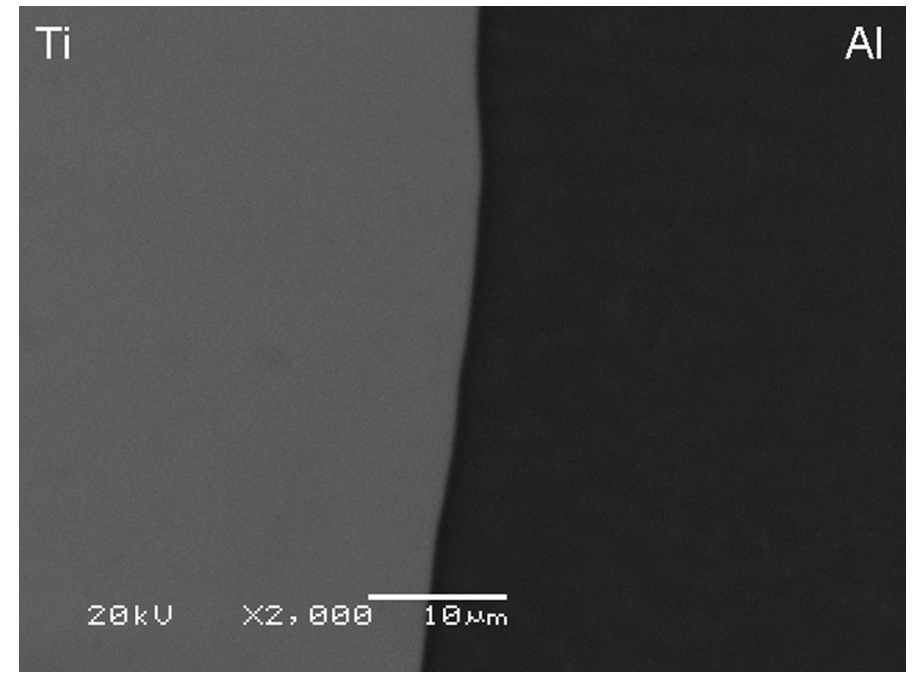

Fig. 1 BSE images of the interface region of samples under aluminum / titanium welded joints without heat treatment.

Typical back-scattered electron (BSE) micrographs of the Al/Ti diffusion couples annealed $9 \mathrm{~h}$ at different temperatures are shown in Fig. 2. It is apparent from Fig. 2 that a dark gray reaction layer appears between the black aluminum alloy and the gray titanium. The EDX analysis shows that this reaction layer is $\mathrm{TiAl}_{3}$, and it is the only new phase of heat generated during the heat treatment process. This result is also consistent with the conclusions in the previous literature [6-8].

As far as the morphology of the reaction layer is concerned, it can be clearly seen from Fig. 2 that the reaction layer is fairly straight and uniform in thickness at different holding times, which is advantageous for us to accurately measure the thickness of the reaction layer and calculation of Growth Activation Energy of the intermetallic compound. As shown in Fig. 2(a-d), the thickness of the $\mathrm{TiAl}_{3}$ reaction layer increases rapidly as the holding temperature increases, and the thickness-temperature relationship shown in Fig. 3 can be obtained by measuring the thickness of the $\mathrm{TiAl}_{3}$ reaction layer

It can be seen from Fig. 3 that the thickness of the aluminum/titanium reaction layer increases rapidly with the increase of the heat treatment temperature under the same holding time and meets the Arrhenius relation, that is, the exponential relationship. This is because the growth of the reaction 
layer is controlled by the diffusion process of the atoms, and the diffusion coefficient of the atoms in the alloy is exponentially related to the temperature. Therefore, the growth rate of the reaction layer is exponentially related to the temperature, and the thickness and temperature are naturally expressed for the exponential relationship.

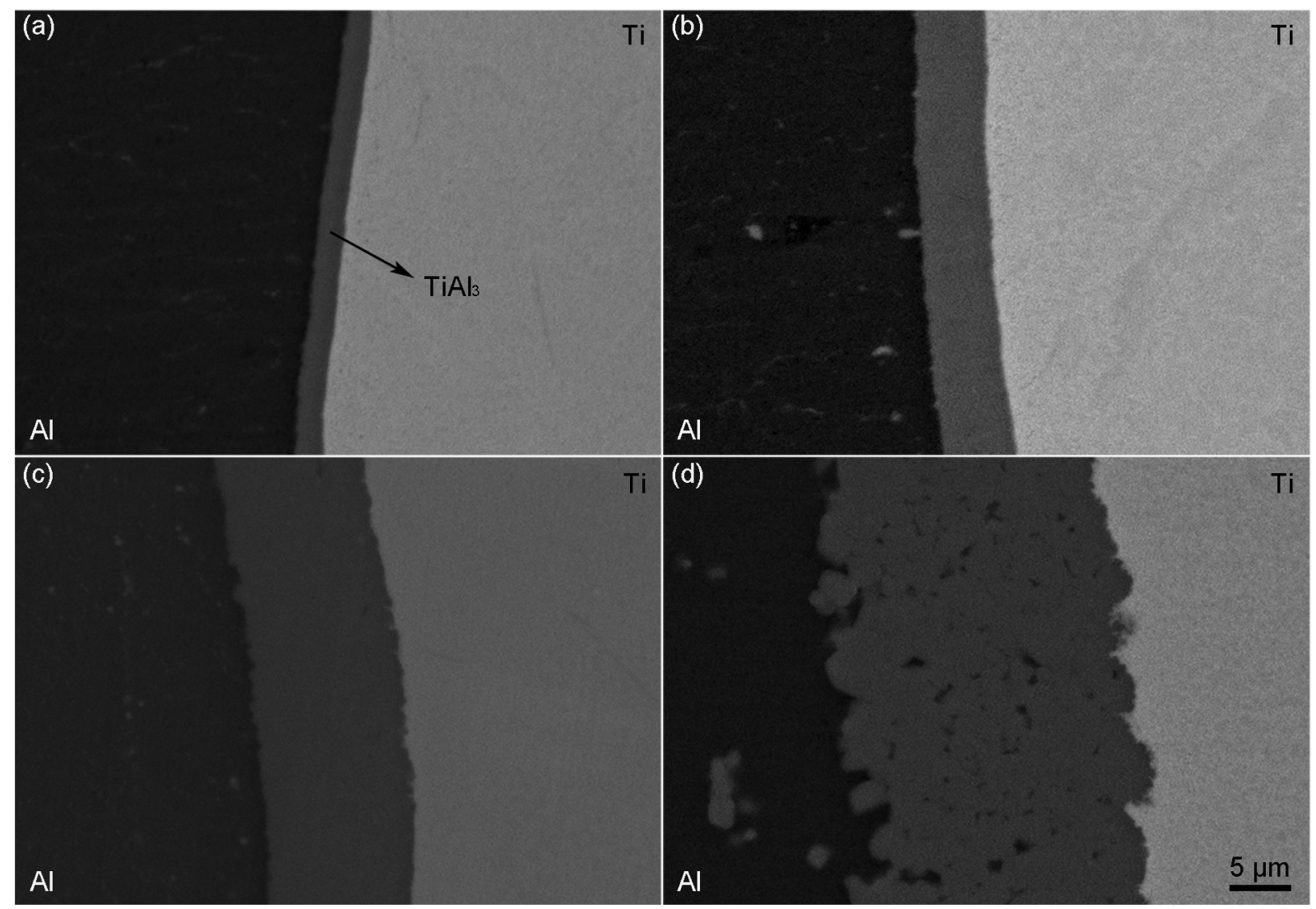

Fig. 2 BSE images of the interface region of samples annealed for $9 \mathrm{~h}$ at $550{ }^{\circ} \mathrm{C}(\mathrm{a}), 575^{\circ} \mathrm{C}(\mathrm{b}), 600{ }^{\circ} \mathrm{C}$ (c) and $630{ }^{\circ} \mathrm{C}(\mathrm{d})$.

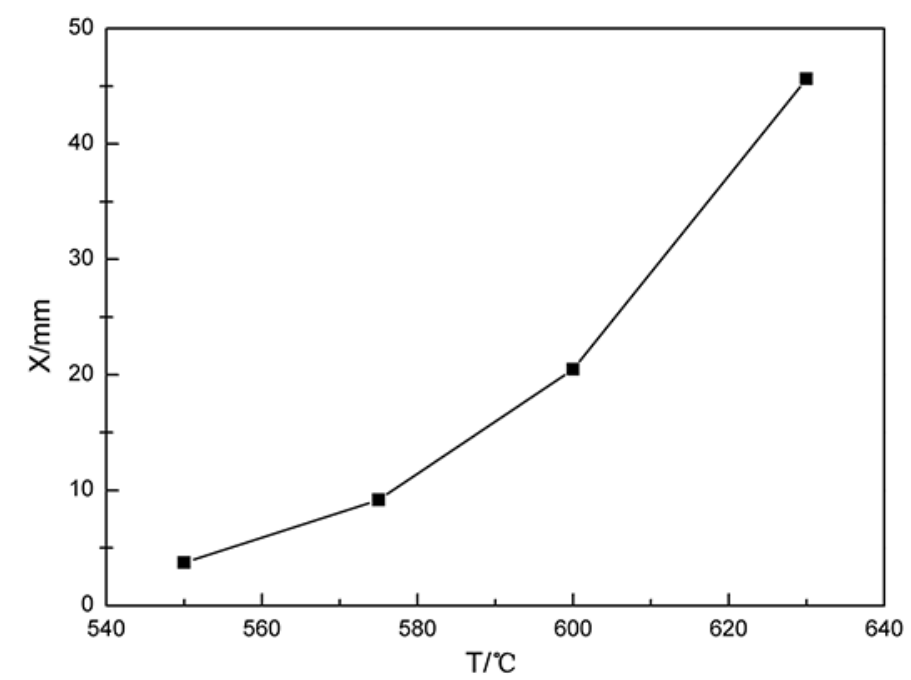

Fig. 3 The relationship between the temperature and the thickness of $\mathrm{TiAl}_{3}$ reaction layer.

\section{Conclusions}

A systematic investigation of the growth of intermetallic $\mathrm{TiAl}_{3}$ in $\mathrm{Ti} / \mathrm{Al}$ couples has been made in the temperature range of $550-630^{\circ} \mathrm{C}$. The main conclusions are summarized as follows: 
1. In agreement with previous investigations, only $\mathrm{TiAl}_{3}$ phase was detected in the $\mathrm{Ti} / \mathrm{Al}$ interface zones in this work.

2. At the same holding time, the thickness of the $\mathrm{Al} / \mathrm{Ti}$ interface reaction layer increases exponentially with the increase of the heat treatment temperature.

\section{Acknowledgements}

This work was supported by the Natural Science Foundation of China (U1204520), Henan Province Support Plan of Universities and Colleges Innovation Talents (16HASTIT050), Henan Province International Science and Technology Cooperation Projects (162102410023)

\section{References}

[1] Nakai M, Eto T. Materials Science \& Engineering A, 2000, 285(1): 62-68.

[2] Faller K, Froes FH. JOM, 2001, 53(4):27-28.

[3] Ren J, Li Y, Tao F. Materials Letters, 2002, 56(5):647-652.

[4] Rohatgi A, Harach D J, Vecchio K S, et al. Acta Materialia, 2003, 51(10):2933-2957.

[5] Peng L M, Wang J H, Li H, et al. Scripta Materialia, 2005, 52(3):243-248.

[6] Xu L, Cui YY, Hao YL, et al. Materials Science \& Engineering A, 2006, s 435-436(4): 638-647.

[7] Luo JG, Acoff VL. Materials Science \& Engineering A, 2004, 379(1-2): 164-172.

[8] Mirjalili M, Soltanieh M, Matsuura K, et al. Intermetallics, 2013, 32(1): 297-302. 